\title{
Microstructural and mechanical characterization of magnesium based alloy MA14 (ZK60 A): evolution under deformation and heat treatment
}

\author{
E. F. Volkova \\ Federal State Unitary Enterprise, "All-Russian Scientific-Research \\ Institute of Aviation Materials”, (FGUP “VIAM”), Russia
}

\begin{abstract}
The interest in magnesium based alloys as structural metal material is due to their low weight, good mechanical and technological properties, high special strength, etc. So magnesium base alloys can compete successfully in physical and mechanical characteristics with other light structural materials especially in the fields where decrease in the mass is of primary significance. The aim of the present work was to study the influence of phase and structural changes in the main properties of commercial magnesium based alloy MA14 (ZK60 A) under deformation and heat treatment parameters. The microstructure was investigated with the use of an optical inverted microscope. The phase composition was investigated by chemical phase analysis with an X-ray analysis of each insulated phase. It is found, that there are primary phases $\mathrm{Mg}_{2} \mathrm{Zn}_{3}, \mathrm{ZrZn}_{2}$ and $\mathrm{Zr}_{3} \mathrm{Zn}_{2}$. Sometimes phases $\varepsilon-\mathrm{ZrH}_{2}, \delta-\mathrm{ZrH}, \mathrm{Zr}_{2} \mathrm{Al}$ can be present in phase composition. All the phases are the hardening ones. The phase quantity, size, morphology correlate with the condition of the magnesium alloy so traditional deformation and heat treatment has not had much influence on qualitative phase composition; only on the phase and grain size. Now it is stated that the most effective processing for receiving the elevated alloy properties is hydrostatic extrusion. The final operation of hydrostatic extrusion of magnesium alloy semi products causes the well-disposed structure and phase changes. Thus the high strength properties of the cheap commercial magnesium alloy MA14 are obtained: tensile strength is more than $380 \mathrm{MPa}$; tensile yield strength is more than $340 \mathrm{MPa}$. Keywords: magnesium alloy, microstructure evolution, hydrostatic extrusion, high strength properties.
\end{abstract}




\section{Introduction}

It is well known structure and phase composition are the major factors influencing the combination of properties of metal alloys. It is possible to control these characteristics of an alloy by changing its chemical composition and technological parameters of its production. The purpose of the present investigation was to study the evolution of phase and structural changes and the main properties of commercial magnesium alloy ZK60A depending on the parameters of deformation and heat treatment.

\section{Material and experiments}

Ingots of Mg-Zn-Zr alloy (ZK60A) were produced by semi-continuous casting and their chemical composition corresponds to the standard composition of the alloy. After machining and homogenization, the ingots were extruded in bars of $\varnothing 40 \mathrm{~mm}$. Different modes of deformation by hydrostatic extrusion (HE) as applied to MA14 alloy bars were studied, in combination with heat treatment (HT) and without it. The technological scheme of deformation consisted of the following stages: extruded bars $\rightarrow( \pm \mathrm{HT}) \rightarrow \mathrm{HE}$ (one - or two steps $) \rightarrow( \pm \mathrm{HT})$. The alloy microstructure was investigated with the use of an optical inverted microscope DMIRM and a scanning electron microscope JSM6490-LV with an additional device INCA450 for X-ray microanalysis. Photos were taken in COMPO mode. Identification of phases was carried out by physical-chemical analysis of chemical isolated phases with their subsequent X-ray spectral and chemical analyses. Quantitative and qualitative X-ray microanalysis was executed with the use of a Superprobe-733 device. Mechanical properties were tested by standard methods of measurement.

\section{Results and discussion}

Research of structure and phase composition of ZK60 A alloy revealed that primary phases $\mathrm{Mg}_{2} \mathrm{Zn}_{3}, \mathrm{ZrZ}_{\mathrm{n} 2}$ and $\mathrm{Zr}_{3} \mathrm{Zn}_{2}$ are in cast state (figs 1 and 2a)). Sometimes formation of low quantities of zirconium compounds with such

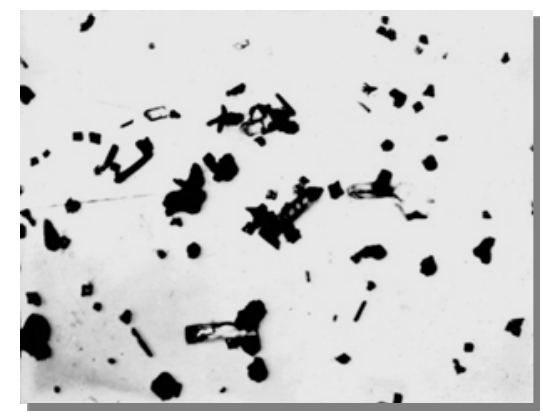

Figure 1: The isolated particles of phases $\mathrm{Zn}_{2} \mathrm{Zr}_{3} \times 10000$. 


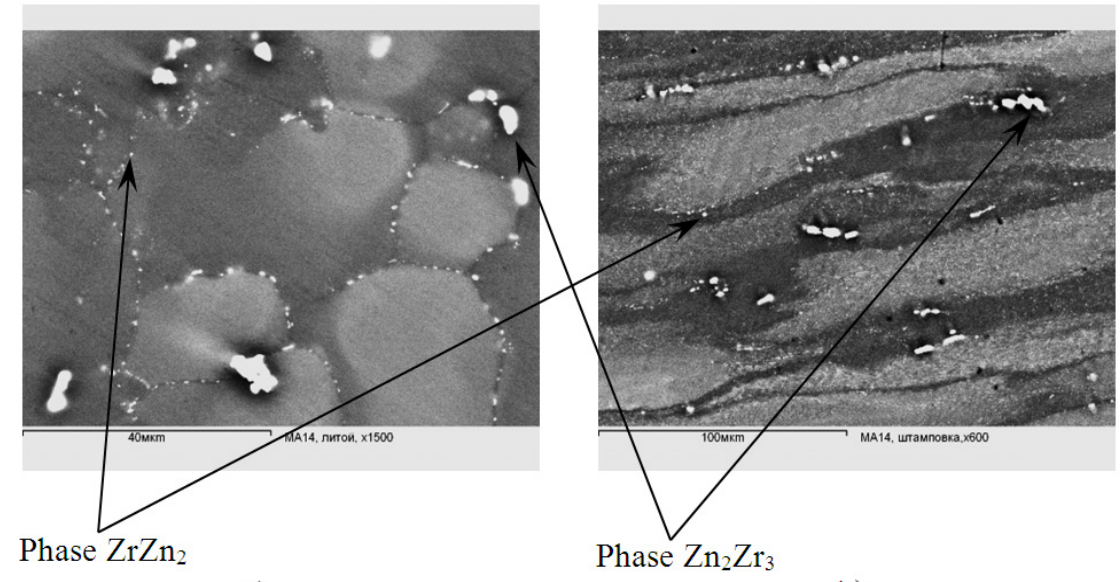

a)

b)

Figure 2: $\quad$ Microstructure of cast ZK60 A alloy casting a) and aged rod with the main primary phases $\mathrm{ZrZn}_{2}, \mathrm{Zn}_{2} \mathrm{Zr}_{3}$ b); longitudinal direction.

impurities as hydrogen and aluminum is possible: $\varepsilon-\mathrm{ZrH}_{2}, \delta-\mathrm{ZrH}$ and $\mathrm{Zr}_{2} \mathrm{Al}[1-$ 3 ]. It is characteristic that the phase composition of the alloy practically does not change after conventional extrusion and subsequent heat treatment (fig. 2a), b)).

The same main phases remain after carrying out HE. However, HE makes some changes of their morphology (fig. 3a), b)).

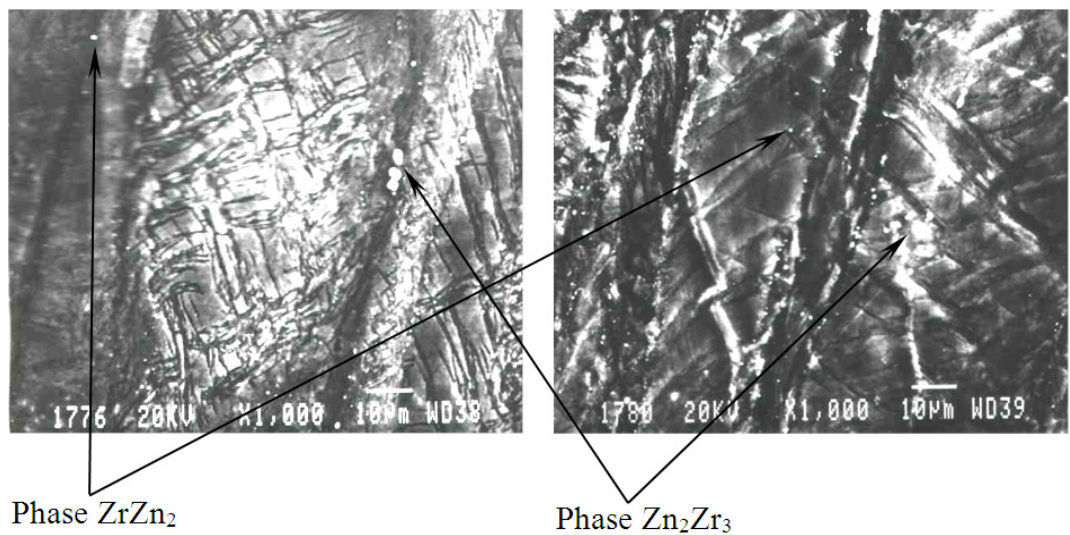

a)

b)

Figure 3: Microstructure of ZK60 A rods after the hydrostatic extrusion: a) after the $I^{\text {st }}$ step of deformation; b) after the $\mathrm{II}^{\text {nd }}$ steps of deformation (longitudinal direction). 
Hydrostatic extrusion is carried out according to the scheme of all-side compression. It provides intensity of sliding and twinning processes in the course of the deformation of magnesium-based alloys $[4,5]$.

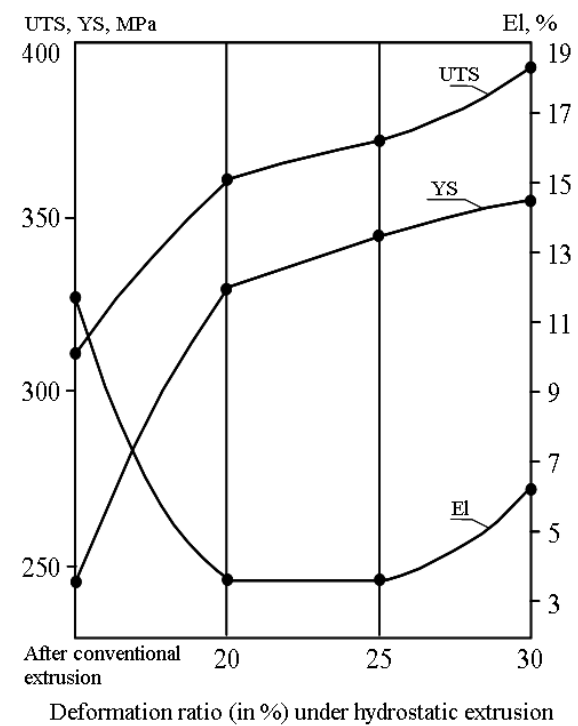

UTS - ultimate tensile strength; YS - yield strength; El - elongation

Figure 4: Evolution of mechanical characteristics of magnesium alloy ZK60 A under hydrostatic extrusion ( $\mathrm{I}^{\text {st }}$ step of HE).

In the case of hydrostatic extrusion, the non-conservative movement of dislocations is activated, formation of dislocation walls occurs, density of mobile dislocations increases and the density of locking dislocations decreases. Thus, hydrostatic extrusion deformation force can be used as an instrument for the formation of alloy microstructure. Comparative research of the alloy microstructure after conventional extrusion and after hydrostatic extrusion confirmed that hydrostatic extrusion causes an effect, which we called "the dynamic phase dispersion effect". First of all, it is related to intermetallic $\mathrm{ZrZn}_{2}$; $\mathrm{Zn}_{2} \mathrm{Zr}_{3}$ phases (figs $2 \mathrm{~b}$ ), 3a), b)). In course of plastic deformation, the diffusion processes are initiated under the action of applied forces and due to an additional increase of internal metal temperature. Along with a probable mechanical crushing of large-sized phases, their partial dissolution and redistribution occurs. It leads to a noticeable refining of phases down to nano-sized particles. Such changes of phase morphology in the alloy microstructure cause an increase of strength properties (fig. 4). The ultimate strength of the alloy is $310-315 \mathrm{MPa}$ after conventional extrusion. Carrying out the one-stage HE with a $30 \%$ deformation ratio leads to a growth of this characteristic up to $375-380 \mathrm{MPa}$. 


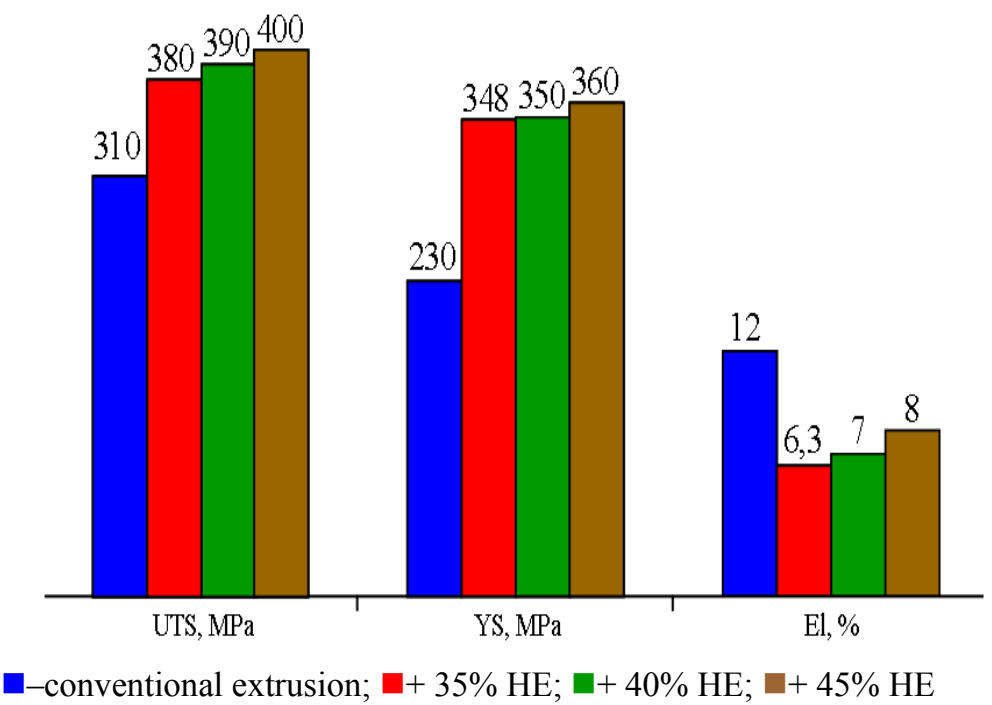

Figure 5: Evolution of mechanical characteristics of ZK60 A magnesium alloy under hydrostatic extrusion (II steps HE).

Accordingly, the yield strength increases from between 240 and $245 \mathrm{MPa}$ up to $340 \mathrm{MPa}$. It should be noted that in the case of deformation by means of onestage hydrostatic extrusion, elongation decreases considerably at the beginning of the process (from 12\% down to 4\%), but later it raises up to 6-7\% (at a 30\% deformation ratio of the one-stage HE). More effective is the two-step HE. In this case, the total deformation is $45 \%$ providing the following level of properties:

UTS $=400 \mathrm{MPa} ;$ YS $=360 \mathrm{MPa}$ at $\delta=8 \%$ (fig. 6). Carrying out of heat treatment after HE intensifies the diffusion processes in the alloy and leads to a noticeable growth and coagulation of phases (fig. 6a), b)). It affects strength properties, which decrease down to the following level: 330-340 $\mathrm{MPa}$ and 235$250 \mathrm{MPa}$ for ultimate strength and yield strength, respectively. At the same time, the values of elongation and reduction in area rise 1.5-2.0 times. Thus, the strengthening effect provided by $\mathrm{HE}$ is reduced substantially and the strength falls down to the level inherent to the state of the alloy after corresponding heat treatment of extruded bars without application of HE.

\section{Conclusion}

1. Changes of structure, phase composition and the main mechanical properties of commercial ZK60 A magnesium alloy depending on parameters of deformation carried out using HE technology and heat treatment were investigated. 


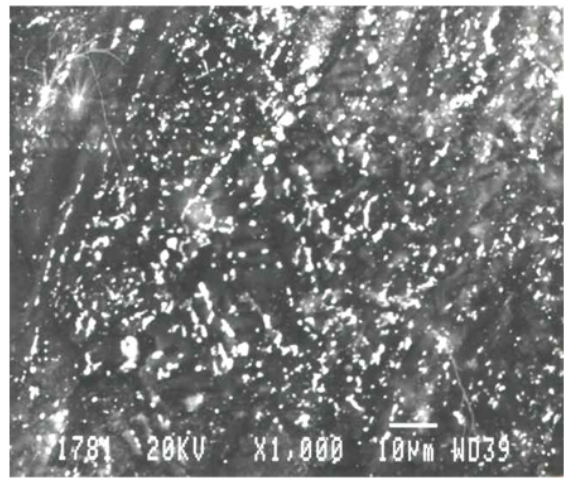

a)

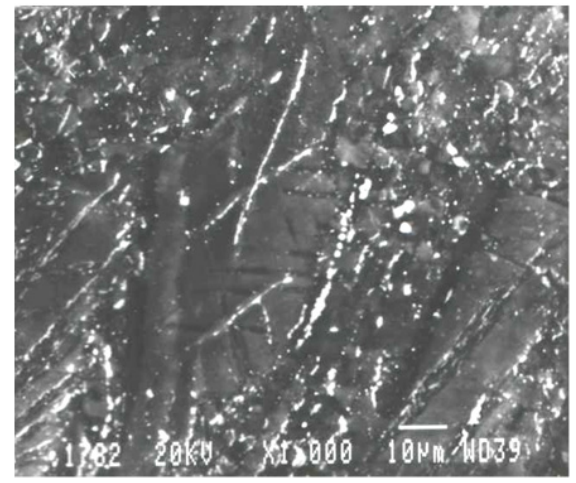

b)

Figure 6: Microstructure of ZK60 A rods after hydrostatic extrusion + heat treatment: a) -aging; b) -annealing + aging.

2. It was stated that application of HE causes the formation of nano-sized particles of the main strengthening phases in the alloy structure owing to mechanical crushing of large phases, their partial dissolution and redistribution. We called this effect "the dynamic phase dispersion effect".

3. It is revealed that the most considerable increase to strength (up to $400 \mathrm{MPa}-$ for UTS and up to $360 \mathrm{MPa}$ - for $0.2 \%$ YS, it is by $\sim 25-40 \%$ ) at sufficient plasticity $(\delta=7-8 \%$ ) can be provided by using the two-step mode of HE.

4. Carrying out the subsequent heat treatment (aging and quenching + aging) of bars subjected to HE leads to loss of strength down to the level corresponding to characteristics of bars subjected to extrusion by conventional technology and heat treatment.

5. The practical importance of the research results consists of a demonstration of the efficiency of HE application to a well-known commercial inexpensive alloy with the purpose of providing a considerable increase in strength.

Thus, advantages and potential of commercial wrought magnesium alloys are not readily used today.

\section{References}

[1] Voikova E.F., Morozova G.I., Structure and Properties of ZirconiumBearing Magnesium Alloy MA14. Metal Science and Heat Treatment, v. 48, N. 1-2, pp. 26-30, 2006.

[2] Volkova E.F., Morozova G.I., The Role of Hydrogen in Deformed Magnesium Alloys of Mg-Zn-Zr-RE System. Metal science and heat treatment, v. 50, N. 3-4, pp. 105-109, 2008. 
[3] Volkova E.F., Iskhodzhanova I.V., Tarasenko L.V., Structural Changes in Magnesium Alloy MA14 under the Action of Process Factors. Metal science and heat treatment, v. 52, pp. 592 -596, 2011.

[4] Volkova E.F., Modern Magnesium Base Deformable Alloys and Composite Materials (A Review). Metal science and heat treatment, v. 48, N. 11-12, pp. 473-478, 2006.

[5] Sillekens W.H., Schade van Westrum J.A.F.M., Bakker A.J. den., Hydrostatic Extrusion of Magnesium. Process mechanics and performance. Materials Science Forum, pp. 629-636, 2003. 